\title{
TREATMENT OF MEDIAL EPICONDYLITIS WITH LOCAL INJECTION OF PLATELET RICH PLASMA
}

\author{
Mohammad Hasan ${ }^{(1)}$ Esam El-Karef ${ }^{(2)}$, Shady Abouelnaga ${ }^{(3)}$ and Islam Erfan ${ }^{(4)}$. \\ (1) Orthopedic and traumatology department, Alexandria University, Egypt. \\ (2) Orthopedic and traumatology department, Alexandria University, Egypt. \\ (3) Consultant of clinical pathology, Alexandria university hospitals. \\ (4) Medical insurance hospitals, Alexandria, Egypt.
}

\begin{abstract}
:
Introduction:: Medial epicondylitis is commonly referred to as "golfer's elbow," and is characterized by pathologic changes to the musculo-tendinous origin at the medial epicondyle. Actually, epicondylitis is not an inflammatory process, but it is a tendinosis that results from tendon microscopic tearing, followed by an incomplete reparative response. Several treatment options are available as nonsteroidal anti-inflammatory medications, physiotherapy, extracorporeal shock wave therapy, local steroid injections and more recently local injection of platelet rich plasma (PRP). Surgery reserved for resistant cases when the mentioned modalities fail.

Patients and method: This study included 27 patients presented to ElHadara University Hospital with chronic symptomatic medial epicondylitis for more than 6 months. All cases received single local injection of PRP and followed up for 3 months after injection. Patients assessment was done using the VAS and DASH scoring system at the initial visit (before injection) and through the follow up period at 2 weeks, 6 weeks and 12 weeks.

Results: Local injection of PRP in cases of medial epicondylitis was a successful method of treatment. When the baseline VAS and DASH scores were compared with the scores at 3 months follow-up, the results showed significant improved across time.

Conclusion: local PRP injection significantly reduced pain and increased function in patients with chronic medial epicondylitis.
\end{abstract}

Key-words: Medial epicondylitis, platelet rich plasma, local injection.

\section{INTRODUCTION}

Lateral and medial epicondylitis are two of the most common causes of elbow pain that occur as a result of sporting and occupational activities. Histologically, it is considered as degenerative changes involving the tendon of the common flexor pronator origin rather than inflammatory changes. The term tendinosis is more accurate. It affects the dominant extremity twice as often as the nondominant. ${ }^{(1,2)}$
Most patients with medial epicondylitis will improve with conservative treatment and time. The most successful regimens of conservative treatment include activity modification and avoidance of precipitating factors as repetitive activities related to work or sport. Other methods of conservative treatment include non-steroidal antiinflammatory drugs (NSAIDs), ice, physical therapy and bracing. Corticosteroid injection may provide temporary relief for periods up to 6 weeks or more, but it doesn't alter the natural history of the disease. Surgical treatment should be considered if symptoms persist beyond 6 months despite nonoperative treatment. ${ }^{(3,4,5)}$

One novel treatment strategy is the use of local injection of platelet-rich plasma (PRP). Preparation of PRP involves centrifugation of autologous blood to separate and extract plasma and buffy coat portions of blood which contain high concentrations of platelets. The platelets may then be activated prior to injection by adding calcium and thrombin to saturate all platelet receptors. Alternatively, the platelets may be naturally activated after injection when it comes in contact with local tissues. These activated platelets then secrete a variety of growth factors which collectively promote the tissue-

Several studies have reported using local PRP injection to treat epicondylitis of the elbow and various other tendinopathies. However, considerable controversy remains about the effectiveness of local platelet-rich plasma injection, which in part may be due to differences in preparation, method of platelet activation, and experimental design, such as how long patients were unresponsive to conservative therapies. $(8,9)$

The goal of this study was to follow the outcome of a single local plateletrich plasma injection in patients with painful medial epicondylitis not responding to conservative treatment 


\section{PATIENTS \& METHODS}

Informed consent was taken from each patient. The current study was a prospective randomized noncontrolled study. It included 27 patients who suffered from chronic medial epicondylitis not responding to conservative treatment for more than 6 months. Patients presented to El-Hadara University Hospital between August 2015 and January 2016. All our patients received a single local injection of PRP and followed up for a period of 3 months after injection. Patients with history of anaemia (hemoglobin $<7.0 \mathrm{~g} / \mathrm{dl}$ ), thrombocytopenia (platelets $<150 \times 103 \mu \mathrm{L}$ ), bleeding dyscrasias or significant cardiovascular, renal and hepatic disease were excluded.

The mean age of the patients was 34.6 \pm 11.5 years (range 18-55 years). Of the 27 patients, there were 21 males (78\%) and 6 females (22\%). All the patients were right handed. The right side was involved in 23 patients $(85.2 \%)$, while both sides were involved in four patients $(14.8 \%) .51 \%$ of the patients were manual workers, $22.2 \%$ were housewives, $11 \%$ were office workers, $7.4 \%$ were athletes, and $7.4 \%$ were students. In 19 patients (70.4\%), medial epicondylitis was not associated with any other pathology, while it was associated with symptomatic snapping ulnar nerve in 5 patients $(18.5 \%)$ and lateral epicondylitis in 3 patients $(11.1 \%)$.

The affected arm lied comfortably abducted and the forearm supinated. The region was disinfected. The most tender point was identified by gentle palpation (approximately one inch distal and radial to the medial epicondyle). The needle was inserted at 90 degrees down to the level of the bone and then pulled back 1 to $2 \mathrm{~mm}$. With a $22 \mathrm{G}$ needle, 2 to $3 \mathrm{ml}$ of The PRP solution was injected via a peppering technique (single skin entry, partially withdrawing the needle, redirecting and making multiple penetrations to the common flexor tendon while injecting equal amounts of PRP). The injected platelets were activated on contact with tendon tissue.

After PRP injection, the patients were instructed to rest their elbow and wrist for 48 hours. Patients were allowed to receive acetaminophen for pain relief while the use of NSAIDs was strictly prohibited. Patients were instructed to avoid NSAIDs for 2 weeks prior to PRP injection as it inhibits the release of the important growth factors needed for the healing process.

The Visual Analogue Scale for pain (VAS) together with the Disability of Arm, Shoulder and Hand (DASH) score were used to assess the patients before injection (base line) and then at 2 weeks, 6 weeks and 12 weeks post injection. Visual Analogue Scale (VAS) measures the amount of pain that a patient feels ranges across a continuum from none (0) to an extreme amount of pain (100).

Data were fed to the computer and analyzed using IBM SPSS software package version 20.0. Qualitative data were described using number and percent. Quantitative data were described using range (minimum and maximum) mean, standard deviation and median. Each patient was used as his or her own control. Paired t test was used to assess the amount of improvement at each follow-up visit as compared with the base line value. Chisquare test was used to test association of the presence of ulnar nerve symptoms and success of treatment. Significance of the obtained results was judged at the $5 \%$ level.

\section{RESULTS}

Initially (before injection), the patients had a mean DASH score of 57.72 and a mean VAS score of 72.65. Two weeks after injection, the DASH score decreased significantly by a mean of $13.3 \%(\mathrm{P}<0.001)$ and the VAS score decreased significantly by a mean of $12.63 \%$ (P <0.001). Six weeks after injection, the DASH score decreased significantly by a mean of $27.56 \%$ in relation to the base line $(\mathrm{P}<0.001)$ and the VAS scores decreased significantly by a mean of $25.9 \%$ in relation to the base line $(\mathrm{P}<0.001)$. After 12 weeks, the DASH score decreased significantly by a mean of $44.9 \%$ ( $\mathrm{P}<0.001)$ and VAS score decreased significantly by a mean of $53.97 \%$ ( $\mathrm{P}<0.001)$. (Table1) (Fig. 1)

\section{Definition of successful and unsuccessful treatment:}

Reduction in DASH score by $25 \%$ or $25 \%$ Reduction in the worst pain score of the VAS was chosen as the primary objective measure of successful treatment after PRP injection. ${ }^{(9)}$ According to this criteria, we had 8 $(29.6 \%)$ non successful patients and 19 (70.4\%) successful patients. All the patients that had associated lateral epicondylitis (3 patients) were successfully treated with PRP injection in contrast to only one of the 5 patients with an associated symptomatic ulnar nerve. There was a significant relation between associated ulnar nerve symptoms and failure of treatment $(P=0.034)$. Table (2)

There was no statistical significance association between the results and age, sex, occupation, side affected, dominant hand and previous treatment. The previous factors did not affect the improvement of the patients during every visits of follow up period. 
Table (1): Comparison between DASH and VAS score changes at every visit in 27 patients

\begin{tabular}{|c|c|c|c|}
\hline & & DASH & VAS \\
\hline Initial (base line) & Mean \pm SD & $57.72 \pm 13.1$ & $72.65 \pm 12.9$ \\
\hline \multirow{3}{*}{2 weeks } & Mean \pm SD & $50.04 \pm 12.26$ & $63.47 \pm 14.13$ \\
\hline & $\mathrm{P}^{*}$ & $<0.001^{*}$ & $<0.001^{*}$ \\
\hline & $\begin{array}{c}\% \text { of change in relation to } \\
\text { the base line }\end{array}$ & $\downarrow 13.3$ & $\downarrow 12.63$ \\
\hline \multirow{3}{*}{6 weeks } & Mean $\pm \mathrm{SD}$ & $41.81 \pm 13.81$ & $53.79 \pm 18.07$ \\
\hline & $\mathrm{P}^{*}$ & $<0.001^{*}$ & $<0.001^{*}$ \\
\hline & $\begin{array}{c}\% \text { of change in relation to } \\
\text { the base line }\end{array}$ & $\downarrow 27.56$ & $\downarrow 25.9$ \\
\hline \multirow{3}{*}{12 weeks } & Mean $\pm \mathrm{SD}$ & $31.75 \pm 17.86$ & $34.66 \pm 29.49$ \\
\hline & $\mathrm{P}^{*}$ & $<0.001^{*}$ & $<0.001^{*}$ \\
\hline & $\begin{array}{c}\% \text { of change in relation to } \\
\text { the base line }\end{array}$ & $\downarrow 44.9$ & $\downarrow 53.97$ \\
\hline
\end{tabular}

Table (2): Relation between success of treatment and presence of associated ulnar nerve symptoms.

\begin{tabular}{|c|c|c|c|c|c|c|}
\hline & \multicolumn{2}{|c|}{ Un Successful } & \multicolumn{2}{|c|}{ Successful } & \multirow{2}{*}{$\chi^{2}$} & \multirow{2}{*}{${ }^{\mathbf{M C}_{\mathbf{p}}}$} \\
\hline & No. & $\%$ & No. & $\%$ & & \\
\hline \multicolumn{5}{|l|}{ Associated Ulnar nerve symptoms } & \multirow{3}{*}{$7.46^{*}$} & \multirow{3}{*}{$0.0063^{*}$} \\
\hline No ulnar nerve symptoms $(n=22)$ & 4 & 18.2 & 18 & 81.8 & & \\
\hline $\begin{array}{l}\text { Ulnar nerve symptoms } \\
(n=5)\end{array}$ & 4 & 80.0 & 1 & 20.0 & & \\
\hline
\end{tabular}

$\chi^{2}$ and $\mathrm{p}$ values for Chi square test for comparing between the two groups

$*$ : Statistically significant at $\mathrm{p} \leq 0.05$

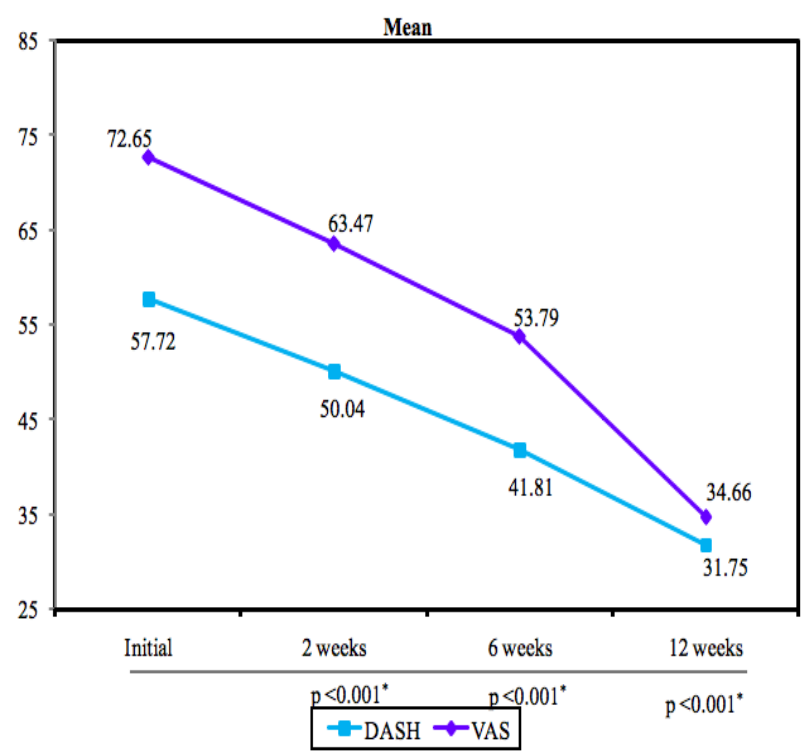

Figure (1): Changes in VAS and DASH scores with every visit.

\section{COMPLICATION}

No complications were reported at any time. There were no infections, neurovascular injuries, or worsening of the patients' pain. The patient uses his own blood and this eliminates all kinds of potential complications as disease transmission and tissue rejection.

\section{DISCUSSION}

Chronic medial epicondylitis is a common problem with many available treatment options. Conservative treatment includes activity modification, rest, NSAIDs and physiotherapy. Local corticosteroid injections are given in acute situations and for cases unresponsive to other conservative methods. Corticosteroid injection offers a quick relief of pain but it has a limited role in chronic cases with high recurrence rate. ${ }^{(9)}$ Jobe and Ciccotti also concluded that of corticosteroid injection may result in 
skin atrophy and permanent adverse effects within the tendon structure. ${ }^{(10)}$

Extracorporeal shock wave therapy also has gained popularity. A randomized double-blind study done in patients suffering from lateral epicondylitis showed that this treatment is not better than placebo. ${ }^{(11)}$

It was estimated that 5-10\% of patients with epicondylitis will need surgery. Surgical treatment of epicondylitis is generally associated with high success rates. ${ }^{(5)}$ However, the morbidity and costs of surgery argue against the surgical option if other options are available. Recently, PRP injection has been used to treat different orthopedic situations like epicondylitis, Achilles tendinopathies and plantar fasciitis. PRP contains a concentrated amount of platelets when injected into the site of tendinosis it promotes cellular chemotaxis, matrix synthesis, and fibroblast proliferation that increases tendon regenerative abilities. $^{(12,13,14)}$

Peerbooms et al, conducted a comparative study between PRP injection and corticosteroid injection in cases of lateral epicondylitis. They reported better outcome with PRP over a period of one year. ${ }^{(9)}$

The goal of our study was to evaluate the outcome of a single local injection of PRP in patients with painful medial epicondylitis after failure of conservative treatment for at least 6 months. This technique was successful in $70.4 \%$ of our patients (19 patients) (a $25 \%$ reduction in worst pain score for at least one follow-up visit). Worst pain scores were significantly better as early as the end of the first month after injection, suggesting a rapid healing response to PRP. The improvement continued through the out the period of follow up. However $29.6 \%$ of our patients (8 patients) were unsuccessfully treated and still had pain at the end of the follow up. They were scheduled for surgery.

Our study showed statistically significant improvement $(\mathrm{P}<0.05)$ in DASH and VAS scores in consecutive follow up visits at 2 weeks, 6 weeks, and 3 months after injection. Initially (before injection), the patients had a mean DASH score of 57.72 and a mean VAS score of 72.65. Two weeks after injection, the DASH score improved by a mean of $13.3 \%$ and the VAS score improved by a mean of $12.63 \%$. Six weeks after injection, the DASH score improved by a mean of $27.56 \%$ in relation to the base line and the VAS score improved by a mean of $25.9 \%$ in relation to the base line. After 12 weeks, the DASH score improved by a mean of $44.9 \%$ and VAS score improved by a mean of $53.97 \%$.

This was similar to what was observed by Swamy and Mishra et al, in the medial epicondylitis group of their study. Initially (before injection), the patients had a mean VAS score of 78.8. Four weeks after injection, the VAS score improved by a mean of $26.7 \%$. Three months after injection, the VAS score improved by a mean of $63.4 \%$ in relation to the base line. ${ }^{(15)}$ Mishra and Pavelko, in their study of PRR injection for lateral and medial epicondylitis showed decreased VAS score from 80.3 (before injection) to 43.4 (4 weeks after injection) to 32.0 (8 weeks after injection) to 5.7 (6 months after injection). ${ }^{(8)}$ Contrary, Glanzmann and Audigé found that local PRP injections for medial epicondylitis didn't show a comparable benefit with that already reported for lateral epicondylitis. They reported a clinical improvement that was insignificant and their patients remained unsatisfied. ${ }^{(16)}$ However, this controversy in part may be due to differences in PRP preparation, method of platelet activation, and how long the patients were unresponsive to conservative treatment.

In our study, there was a strong association between the presence of associated ulnar nerve symptoms and treatment failure. $50 \%$ of unsuccessfully treated cases had ulnar nerve symptoms and they were electrophysiologically free. Gabel and Morrey, ${ }^{(17)}$ classified medial epicondylitis according to the level of the associated ulnar neuropathy. They showed that the prognosis for Type II (associated ulnar nerve affection) medial epicondylitis was worse than the prognosis for Type I (no associated ulnar nerve affection), it is for this reason that careful diagnosis, and treatment of patients with ulnar nerve symptoms frequently determines outcome. $^{(17)}$

Limitations of our study were the small number of patients and lack of a control group and the short period of follow up.

\section{CONCLUSION}

The results of this study suggest that PRP injection can relieve pain and improve function in patients with longterm medial epicondylitis who had failed conservative treatment. This technique was efficient in approximately $70.4 \%$ of affected patients at 3 month follow-up. PRP is simple to acquire and prepare and is also cost effective when compared with surgery.

\section{REFERENCES}

1. Verhagen AP, Bierma-Zeinstra SM, Burdorf A, Stynes $\mathrm{SM}$, de Vet HC, Koes BW. Conservative interventions for treating work-related complaints of the arm, neck or shoulder in adults. Cochrane Database Syst Rev 2013;12:CD008742.

2. Kraushaar BS, Nirschl RP. Tendinosis of the elbow. Clinical features and findings of histological, immunohistochemical and electron microscopy studies. J Bone Joint Surg Am 1999; 81(2):259-78.

2. Wang JH, Iosifidis MI, Fu FH. Biomechanical basis for tendinopathy. Clin Orthop Relat Res 2006; (443):320-32.

3. Wong MW, Tang YY, Lee SK, Fu BS, Chan BP, Chan CK. Effect of dexamethasone on cultured human tenocytes and its reversibility by platelet-derived growth factor. J Bone Joint Surg Am 2003; 85(10):1914-20.

4. Wong MW, Tang YY, Lee SK, Fu BS. Glucocorticoids suppress proteoglycan production by human tenocytes. Acta Orthop 2005; 76(6):927-31. 
5. Andres BM, Murrell GA. Treatment of tendinopathy: what works, what does not, and what is on the horizon. Clin Orthop Relat Res 2008; 466 (7):1539-54.

6. Alsousou J, Thompson M, Hulley P, Noble A, Wilett K. The biology of platelet-rich plasma and its application in trauma and orthopaedic surgery: a review of the literature. J Bone Joint Surg Br 2009;91(8):987-96.

7. Foster TE, Puskas BL, Mandelbaum BR, Gerhardt MB, Rodeo SA. Platelet-rich plasma: from basic science to clinical applications. Am J Sports Med 2009; 37(11): 2259-72.

8. Mishra A, Pavelko T. Treatment of chronic elbow tendinosis with buffered platelet-rich plasma. Am J Sports Med 2006; 34 (11):1774-8.

9. Peerbooms JC, Sluimer J, Bruijn DJ, Gosens T. Positive effect of an autologous platelet concentrate in lateral epicondylitis in a double-blind randomized controlled trial: platelet-rich plasma versus corticosteroid injection with a 1-year follow-up. Am J Sports Med 2010; 38(2): 255- 62 .

10. Jobe F, Ciccotti M. Lateral and medial epicondylitis of the elbow. J Am Acad Orthop Surg 1994; 2:1-8.
11. Melikyan E, Shahin E, Miles J, Bainbridge L. Extracorporeal shockwave treatment for tennis elbow: a randomized double-blind study. J Bone Joint Surg 2003; 85B: 852-855.

12. Michael P. Hall, MD, Phillip A. Band, PhD, Robert J. Meislin. Platelet-rich Plasma: Current Concepts and Application in Sports Medicine. J Am Acad Orthop Surg 2009; 17: 602-8.

13. Marx R, Carlson E, Eichstedt R. Platelet rich plasma: growth factor enhancement for bone and grafts. Oral Surg Oral Med Oral Pathol 1998; 85(6): 643-6.

14. An evidence-based evaluation on the use of platelet rich plasma in orthopedics - a review of the literature. SICOT J 2017; 3: 57.

15. Swamy L K, Mishra A, Sadangi B , Hota S, Behera S K, Patra S. Platelet-Rich Plasma Injections In The Management Of Chronic Tendinopathies.JDMS 2017; 16(5) 41-51.

16. Glanzmann MC1, Audigé L. Efficacy of platelet-rich plasma injections for chronic medial epicondylitis. J Hand Surg Eur 2015;40 (7):744-5.

17. Gabel GT, Morrey BF. Medial epicondylitis. In: Morrey BF (ed). The elbow and its disorders. 4th ed. New York: Elsevier Health Sciences; 2008. 643-702. 